\title{
MAPA DE EROSÃO DO ESTADO DE SÃO PAULO
}

\author{
Fernando Facciolla KERTZMAN \\ Antonio Manoel S. OLIVEIRA \\ Fernando Ximenes T. SALOMÃO \\ Maria Isabel Faria GOUVEIA
}

\begin{abstract}
RESUMO
O objetivo principal deste trabalho é apresentar a metodologia utilizada na elaboração do mapa de suscetibilidade à erosão do Estado de São Paulo, em escala 1:250.000, um dos produtos do Projeto "Orientações para o combate à erosão no Estado de São Paulo", que está sendo desenvolvido sob coordenação do Departamento de Águas e Energia Elétrica - DAEE e Instituto de Pesquisas Tecnológicas do Estado de São Paulo - IPT, com cooperação técnica do Instituto Agronômico de Campinas - IAC e Instituto de Pesquisas Espaciais - INPE.

O mapa-síntese de erosão do Estado de São Paulo, em fase de conclusão, destaca áreas com diferentes comportamentos erosivos, tendo em vista as potencialidades dos terrenos à produção de sedimentos e conseqüente assoreamento dos corpos d'água, ou seja, o impacto da erosão nos recursos hídricos superficiais.
\end{abstract}

\section{ABSTRACT}

This work presents the methodology used in the elaboration of the erosion susceptibility map of São Paulo State, at the 1:250.000 scale. This map is one of the results of the Project "Orientations for the erosion control in the São Paulo State", which has been, jointly conducted by the Departamento de Águas e Energia Elétrica and the Instituto de Pesquisas Tecnológicas do Estado de São Paulo - IPT, with technical cooperation of Instituto Agronômico de Campinas - IAC and Instituto de Pesquisas Espaciais - INPE.

The synthesis map of the erosion processes in the state of São Paulo (in conclusion), stresses areas with different erosion properties, considering the natural tendency of production of sediments and consequent silting of water courses. These informations permit an evaluation of the impact of erosion processes on surficial water resources.

\section{INTRODUÇÃO}

A ocupação humana - iniciada pelo desmatamento e seguida pelo cultivo da terra, implantação de estradas, criação e expansão das vilas e cidades, sobretudo quando efetuada de modo inadequado - constitui o fator decisivo da origem e aceleração dos processos erosivos atuais. Deflagrados pela ocupação do solo, estes processos erosivos passam a ser comandados por diversos fatores naturais relacionados às características da chuva, do relevo, do solo e da cobertura vegetal. A freqüência da manifestação dos processos erosivos do tipo laminar e em sulcos e o desenvolvimento de ravinas profundas e boçorocas mobilizam milhares de $\mathrm{m}^{3}$ de sedimentos em pouco tempo, destruindo terras de cultura, equipamentos urbanos e obras civis. No Estado de São Paulo, estima-se que $80 \%$ da área cultivada esteja sofrendo processo erosivo além dos limites de tolerância, representando uma perda anual de aproximadamente 200 milhões de toneladas de terra, com prejuízos econômicos fabulosos, tanto pela queda de produtividade, perda de fertilizantes/sementes, como pelas necessidades de maiores investimentos, na recuperação do solo (LOMBARDI \& BERTONI, 1985). Levantamentos em realização pelo IPT (1986, 1988, 1990 e 1992) permitem estimar para o Estado de São Paulo a existência de aproximadamente 10.000 boçorocas. O custo das obras corretivas exigiria valores astronômicos, inviáveis de serem aplicados pelo poder público a curto e médio prazos, sem considerar os custos envolvidos pela necessidade de recompor áreas urbanas degradadas, suas edificações, arruamentos etc., e obras viárias interrompidas ao 
tráfego por problemas erosivos, sobretudo na época das chuvas.

Parte dos sedimentos provenientes da erosão deposita-se em posições determinadas das vertentes, destruindo solos férteis, e outra parte pode atingir o fundo dos vales, provocando assoreamentos de cursos d'água ou de reservatórios. O assoreamento constitui um dos mais graves impactos da erosão no meio ambiente, desequilibrando as condições hidráulicas, promovendo enchentes, perdas de capacidade de armazenamento d'água, o incremento de poluentes químicos e gerando prejuízos ao abastecimento e produção de energia.

Através de um convênio firmado em 1985 entre o DAEE e o IPT, estudos de diagnóstico e prognóstico da erosão e do assoreamento vêm sendo realizados através do projeto "Orientações para o combate à erosão no Estado de São Paulo". Este projeto deverá ser concluído em todo o Estado em 1993 e vem sendo implementado nas áreas correspondentes às regiões administrativas do DAEE, visando definir as bases técnicas e subsídios para uma política estadual de combate à erosão, ao nível preventivo e corretivo. Entre os principais produtos contemplados pelo projeto, destaca-se a apresentação de mapas temáticos, em escala 1:250.000, abordando os seguintes tópicos:

- uso e ocupação atual do solo;

- ocorrências de erosão por ravinas e boçorocas;

- mapa de suscetibilidade à erosão laminar;

- mapa de suscetibilidade à erosão por ravinas e boçorocas;

- mapa de suscetibilidade à erosão total (laminar + ravinas e boçorocas);

- impacto da erosão nos recursos hídricos.

A erosão por ravinas e boçorocas é o processo que provoca maior impacto no meio físico, nas obras e nos recursos hídricos. Neste artigo destacamos este produto para ser apresentado. A figura 1 apresenta o mapa de erosão devido a ravinas e boçorocas, de forma sintética, de maneira a ilustrar o trabalho com um dos produtos anteriormente relacionados.

Neste trabalho são abordadas as questões relativas à metodologia empregada na elaboração deste produto e uma síntese dos principais resultados.

\section{PROCEDIMENTOS METODOLÓGICOS PRINCIPAIS}

O quadro 1 apresenta o roteiro metodológico geral utilizado na elaboração dos mapas de risco à erosão. Os trabalhos foram conduzidos para identificar os fatores naturais e antrópicos que condicionam a erosão. Estes fatores foram cartografados na escala 1:250.000. A partir desses mapas temáticos foram elaborados mapas de síntese, que indicam a suscetibilidade natural dos terrenos à erosão.

\section{QUADRO 1 - Roteiro Metodológico Geral}

\begin{tabular}{cccc}
\hline EROSÃO & OCORRÊNCIA & GEOLOGIA & SUSCETIBILIDADE \\
LINEAR & DE & + GEOMORFOLOGIA & A RAVINASE \\
& BOÇOROCAS & PEDOLOGIA & BOÇOROCAS \\
\hline
\end{tabular}

2.1 Mapas de Suscetibilidade à Erosão Devido a Ravinas e Boçorocas

A metodologia desenvolvida pelo IPT/DAEE para a elaboração de mapas de suscetibilidade à erosão por ravinas e boçorocas baseia-se na análise integrada da paisagem (KILIAN \& ROSSELLI, 1978; IWASA et al., 1987), ponderando-se o comportamento da água e incidências dos processos erosivos, em relação aos fatores geológicos, geomorfológicos e pedológicos (IPT, 1986).

Essa metodologia - descrita por OLIVEIRA et al. (1987) e PONÇANO et al. (1987 a e b) - envolve os seguintes passos:

a) cadastramento das ocorrências de ravinas e boçorocas, através de interpretação de fotografias aéreas mais atualizadas possíveis, em escala 1:250.000. Essa interpretação procura distinguir os processos erosivos de "reativação de drenagem" e os processos erosivos relacionados a concentrações de águas pluviais. Esse procedimento é um primeiro passo para destacar áreas mais ou menos suscetíveis a fenômenos de "piping" (boçorocamento), normalmente relacionados a processos erosivos de reativação de drenagem, especialmente em cabeceiras de cursos d'água. As ocorrências identificadas são locadas em mapas-bases, constituindo-se em mapas de ocorrências de ravinas e boçorocas;

b) elaboração, numa mesma escala, de mapas geológicos, geomorfológicos e pedológicos. Esses mapas devem ser previamente interpretados visando ao estudo dos processos erosivos devido a ravinas e boçorocas. O mapa geológico deve ser interpretado visando à distinção de diferentes litologias agrupadas em função do seu comportamento frente aos fenômenos de ravinamento e boçorocamento; o mapa geomorfológico, interpretado de maneira a distinguir áreas representativas de cabeceiras de drenagens e áreas homogêneas quanto aos sistemas/formas de relevo e feições geomorfológicas; o mapa pedológico, interpretado de manei- 


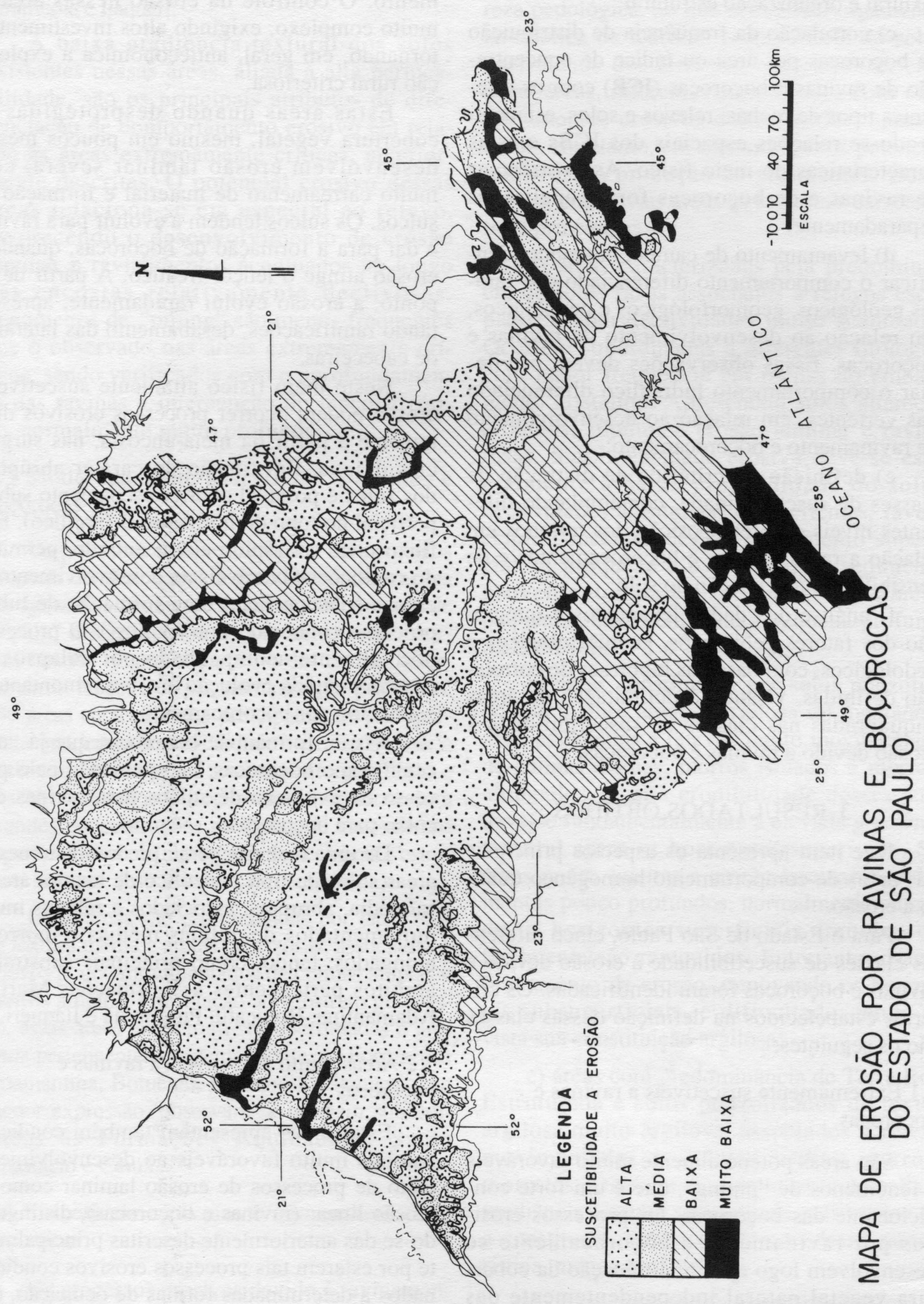


ra a agrupar solos com características comuns em relação à profundidade, textura, gradiência textural e organização estrutural;

c) correlação da freqüência de distribuição de boçorocas por área ou índice de concentração de ravinas e boçorocas (ICB) com os diferentes tipos de rochas, relevos e solos, estabelecendo-se relações espaciais dos ICBs e estas características do meio físico. As ocorrências de ravinas e de boçorocas foram analisadas separadamente;

d) levantamento de campo, buscando identificar o comportamento diferenciado dos fatores geológicos, geomorfológicos e pedológicos, em relação ao desenvolvimento de ravinas e boçorocas. Essas observações devem privilegiar o comportamento hidráulico diferenciado das vertentes, em relação ao desenvolvimento de ravinamento e boçorocamento;

e) definição de critérios de distinção de classes de suscetibilidade, contemplando diferentes níveis de predisposição dos terrenos em relação a ravinamentos e boçorocamentos e de sensibilidade à ocupação do solo;

f) análise dos dados levantados e integração dos fatores geológicos, geomorfológicos e pedológicos, com base nas hipóteses de correlação definidas, visando à delimitação de áreas enquadradas nas classes de suscetibilidade à erosão devido a ravinas e boçorocas.

\section{RESULTADOS OBTIDOS}

Este item apresenta os aspectos principais das áreas de comportamento homogêneo quanto à erosão.

Para o Estado de São Paulo, cinco diferentes classes de suscetibilidade à erosão devido a ravinas e boçorocas foram identificadas. Os critérios estabelecidos na definição dessas classes são os seguintes:

\subsection{Extremamente suscetíveis a ravinas e boçorocas}

São áreas potencialmente muito favoráveis a fenômenos de "piping", que é um forte condicionante das boçorocas. Os processos erosivos por ravinamento e boçorocamento se desenvolvem logo após a eliminação da cobertura vegetal natural independentemente das formas de ocupação. As áreas assim caracterizadas correspondem às regiões mais afetadas por processos erosivos no Estado de São Paulo. Apresentam condições naturais muito favoráveis ao desenvolvimento tanto da erosão laminar como da erosão linear, por ravinas e boçorocas. Grande parte dessas áreas caracteriza-se pela possibilidade de deflagração dos processos erosivos independentemente de formas de ocupação do solo, a partir do desmatamento. O controle da erosão nessas áreas é muito complexo, exigindo altos investimentos, tornando, em geral, antieconômica a exploração rural criteriosa.

Estas áreas quando desprotegidas da cobertura vegetal, mesmo em poucos meses, desenvolvem erosão laminar severa, com muito carreamento de material e formação de sulcos. Os sulcos tendem a evoluir para ravinas e daí para a formação de boçorocas, quando a erosão atinge o lençol freático. A partir de tal ponto, a erosão evolui rapidamente, apresentando ramificações, desabamento das laterais e de cabeceiras.

Neste meio físico altamente suscetível à erosão podem ocorrer processos erosivos diretamente a partir da meia-encosta, nas surgências d'água. Em função do caráter abrúptico dos solos é possível ocorrer escoamento subsuperficial no topo do horizonte B (argílico). Este fluxo pode ser rápido e concentrado, permitindo condições favoráveis ao desenvolvimento de erosão subsuperficial com formação de tubos, processo conhecido por "piping". O processo, normalmente acompanhado por colapsos do terreno e rápida evolução erosiva remontante, é conhecido por boçorocamento.

Assim, formam-se boçorocas que já "nascem" como boçorocas, não passando pelo processo de evolução de sulcos para ravinas e aí então para boçorocas.

De uma maneira geral, predominam nessas áreas solos do tipo podzólico de textura areno$\mathrm{sa} /$ média, abruptos, associados a relevos muito movimentados de colinas médias e morrotes alongados, tendo, como principais substratos, arenitos pertencentes às Formações Marília, Adamantina, Botucatu, Pirambóia e Itaqueri.

\section{2 Áreas muito suscetíveis a ravinas e boçorocas}

Estas áreas apresentam também condições naturais muito favoráveis ao desenvolvimento tanto de processos de erosão laminar como de erosão linear (ravinas e boçorocas), distinguindo-se das anteriormente descritas principalmente por estarem tais processos erosivos condicionados a determinadas formas de ocupação, que permitam a concentração das águas de escoamento superficial.

Predominam, nas áreas muito suscetíveis, solos do tipo podzólico de textura arenosa/média e média, não abruptos, latossolos de textura média e areias quartzosas, associados a relevos movimentados de colinas médias e morrotes alongados. O substrato geológico constitui-se fundamentalmente 
por arenitos pertencentes às Formações Itararé, Adamantina, Caiuá, Santo Anastácio, Botucatu, Pirambóia e Itaqueri.

A baixa gradiência textural dos solos existentes nessas áreas, aliada à alta permeabilidade, são os principais atributos de diferenciação de comportamento erosivo em relação às áreas extremamente críticas, anteriormente descritas. O potencial erosivo dessas áreas relaciona-se em especial ao relevo, favorecendo o desenvolvimento de erosão laminar e ravinamentos acentuados ao longo das encostas relativamente declivosas. Fenômenos de "piping" são menos freqüentes que o observado nas áreas extremamente críticas, sendo verificados com o aprofundamento das ravinas e intercepção do lençol freático, normalmente muito profundo.

\subsection{Moderadamente suscetíveis a ravinas e boçorocas}

Os processos erosivos devido a ravinamentos ocorrem condicionados a grandes concentrações das águas de escoamento superficial; fenômenos de "piping" desenvolvendo boçorocas somente ocorrem quando o aprofundamento das ravinas interceptam o lençol freático, normalmente profundos. São áreas caracterizadas principalmente por apresentar moderada suscetibilidade à erosão laminar e potencial favorável ao ravinamento profundo e desenvolvimento de boçorocas, condicionado a grandes concentrações de águas de escoamento superficial, especialmente através de "obras e estruturas lineares" (estradas, cercas, caminhos...).

Estas áreas são representadas por latossolos de textura média e areias quartzosas, associadas a relevos pouco movimentados de colinas amplas e morros amplos. Em relação ao substrato geológico, essas áreas encontram-se subordinadas a arenitos pertencentes, principalmente, às Formações Adamantina, Botucatu, Pirambóia e Itaqueri. Em menor expressão, observam-se também subordinadas às Formações Aquidauana, Santo Anastácio e Caiuá.

3.4 Suscetíveis a ravinas e não suscetíveis a boçorocas

Os processos erosivos devido a ravinamentos ocorrem condicionados a declividades das encostas e a determinadas formas de ocupação do solo; em geral as ravinas são pouco profundas, tendo em vista a resistência imposta pelos horizontes subsuperficiais do solo.

São áreas não suscetíveis a boçorocas, sujeitas exclusivamente a ravinamentos pouco profundos e à erosão laminar, cuja intensidade é ditada principalmente pela declividade das vertentes. Dependendo especialmente da natureza pedológica, no que se refere à organização latossólica ou textural, profundidade do solo e declividade dos terrenos, observam-se, entre essas áreas, diferentes subunidades com comportamentos erosivos determinados, apresentando, entretanto, em comum, baixos potenciais relativos na produção de sedimentos. Destacam-se entre essas áreas as seguintes características principais:

a) áreas caracterizadas pela predominância de solos rasos associados a relevos escarpados e com declividades muito acentuadas. Ocorrem subordinadas a diferentes litologias, com maior freqüência em rochas do embasamento cristalino. Apresentam solos altamente erodidos, sujeitos a erosão laminar e ravinas rasas. Sua intensidade erosiva deve-se especialmente à baixa profundidade do solo e declividades acentuadas das vertentes, favorecendo concentrações do escoamento superficial. A produção e o acúmulo de sedimentos provenientes da erosão são relativamente pequenos, tendo em vista a pequena profundidade do solo;

b) áreas constituídas por solos podzolizados de textura arenosa/argilosa ou média/argilosa, associados a relevos muito movimentados de colinas médias, morros isolados e morrotes alongados. A alta erodibilidade desses solos deve-se fundamentalmente à elevada gradiência textural entre os horizontes superiores. São áreas muito sujeitas a erosão laminar e ravinamentos pouco profundos, normalmente atingindo os horizontes superficiais arenosos que facilmente são removidos. Entretanto, o aprofundamento da erosão, removendo os horizontes subsuperficiais, é dificultado, tendo em vista sua constituição argilosa;

c) áreas com predominância de Terra Roxa Estruturada e solos podzolizados de textura argilosa/muito argilosa, associados a relevos movimentados de colinas médias, morros e morrotes. Diferem dos anteriores pela baixa gradiência textural apresentada pelos solos que a constituem, sendo, em função dessa característica, menos erodível;

d) caracterizadas pela ocorrência de solos latossolizados de textura argilosa, associados a relevos movimentados de colinas médias, morros e morrotes. A profundidade, relativamente elevada, alta permeabilidade e estrutura microagregada são características importantes que dão a estas áreas comportamento erosivo qualificado por baixa suscetibilidade à erosão laminar e ao ravinamento, 
manifestando-se somente quando submetidas a grandes concentrações de águas superficiais;

e) áreas constituídas por latossolos argilosos em relevos suaves de colinas amplas e morro amplos. Apresentam características ero-

\section{REFERÊNCIAS BIBLIOGRÁFICAS}

DEPARTAMENTO DE ÁGUAS E ENERGIA ELÉTRICA - DAEE. 1990. "Controle de Erosão". Secretaria de Energia e Saneamento do Estado de São Paulo. 2 $2^{\mathrm{a}}$ Edição.

INSTITUTO DE PESQUISAS TECNOLÓGICAS DO ESTADO DE SÃO PAULO - IPT. 1986. Orientações para o combate à erosão no Estado de São Paulo, Bacia do Peixe-Paranapanema. São Paulo, 1986, 6 vols. (IPT, Relatório, 24.739).

1988. Orientações para o combate à erosão no Estado de São Paulo, Bacia do Baixo Tietê. São Paulo, 1988, 4 vols. (IPT, Relatório 26.989).

1990. Orientações para o combate à erosão no Estado de São Paulo, Bacia do Pardo Grande. São Paulo, 1990, 2 vols. (IPT, Relatório 28.184).

1992. Orientações para o combate à erosão no Estado de São Paulo, Bacia do Médio Tietê, São Paulo, 1992. (IPT, Relatório 29.004).

IWASA, O.Y. et al. 1987. Áreas de risco ao desenvolvimento de erosão por ravinas e boçorocas na Folha de Marília, SF-22-2A. In: SIMPÓSIO NACIONAL DE CONTROLE DE EROSÃO, 4o, Marília, 1987. Anais. São Paulo: ABGE, p. 137-148. sivas semelhantes às áreas anteriormente descritas, diferindo por apresentar baixas declividades de encostas, sendo em função disso menos suscetíveis à erosão.

3.5 Áreas de agradação: não ocorre erosão.
KILIAN, J. \& ROSSELLI, J.F. 1978. "La cartografia morfopedologica del Instituto de Investigaciones Agronomicas Tropicales y de Cultivos Comestibles". IX Conferencia Internacional de Cartografia. Maryland.

LOMBARDI NETO, F. \& BERTONI, J. 1975. Erodibilidade dos solos paulistas. Campinas, SP. Instituto Agronômico, Boletim Técnico, 27.

OLIVEIRA, A.M. dos S. et al., 1987. Questões metodológicas em diagnósticos regionais de erosão: a experiência pioneira da Bacia do Peixe-Paranapanema, SP. In: SIMPÓSIO NACIONAL DE CONTROLE DE EROSÃO, 4, Marília, 1987. Anais. São Paulo: ABGE, p. 51-71.

PONÇANO, W.L.; SALOMÃO, F.X. de T.; KERTZMAN, F.F.; IWASA, O.Y., 1987. Discriminação de áreas com diferentes suscetibilidades à erosão por boçorocas e ravinas na Bacia do Peixe-Paranapanema, SP. In: CONGRESSO BRASILEIRO DE GEOLOGIA DE ENGENHARIA, 5, São Paulo, 1987. Anais. São Paulo: ABGE, p. 423-429.

PONÇANO, W.L.; KERTZMAN, F.F.; SALOMÃO, F.X. de T. 1987. Fatores geológicos, geomorfológicos e pedológicos no desenvolvimento de boçorocas na Bacia do Peixe-Paranapanema, SP. In: CONGRESSO BRASILEIRO DE GEOLOGIA DE ENGENHARIA, 5º São Paulo, 1987. Anais. São Paulo: ABGE, p. 413-422.

Endereço dos autores:

Fernando Facciolla Kertzman, Antonio Manoel S. Oliveira e Fernando Ximenes T. Salomão - Instituto de Pesquisas Tecnológicas do Estado de São Paulo S/A - Cidade Universitária Armando Salles de Oliveira - Butantã - Caixa Postal 7141 - 05508-901 - São Paulo, SP Brasil.

Maria Isabel Faria Gouveia - Departamento de Águas e Energia Elétrica - DAEE - Rua Riachuelo, 115 - $4^{\circ}$ andar - Caixa Postal 9319 01007-000 - São Paulo, SP - Brasil. 